\title{
Lack of Awareness of Partner STD Risk Among Heterosexual Couples
}

CONTEXT: Individuals' accurate assessment of their exposure to the risk of HIV and other STDs requires awareness of their sexual partners' risk behaviors and disease status.

METHODS: In a sample of 217 couples enrolled in a risk intervention trial in 1997-2002, both partners reported on their own risk behaviors and their perceptions of their partner's behavior; concordance of partners' reports was examined using kappa statistics. Individual and relationship characteristics predicting lack of awareness of a partner's risk behavior were explored using multivariate logistic regression.

RESULTS: Three percent of women and 14\% of men were unaware that their partner had recently had a concurrent partner. Eleven percent and 12\%, respectively, were unaware that their partner had ever injected drugs; $10 \%$ and $12 \%$ were unaware that their partner had recently received an STD diagnosis; and 2\% and 4\% were unaware that their partner was HIV-positive. Women's lack of awareness of partner risk was associated with increasing age (odds ratio, 1.1), being of a race or ethnicity other than black or Latina (15.8) and having a Latino partner (3.7); it was positively associated with a man's report that he was married (4.4) and with relationship satisfaction as reported by both the woman and her partner (1.2 for each). Among men, lack of awareness was positively associated with partner's age (1.1) and with having a partner who was formerly married (8.2).

CONCLUSIONS: Couple-based interventions that assess each partner's awareness of the other's risk behavior may help programs better target couples' STD prevention needs.

Perspectives on Sexual and Reproductive Health, 2010, 42(1):49-55, doi: 10.1363/4204910
By Susan S. Witte, Nabila El-Bassel, Louisa Gilbert, Elwin Wu and Mingway Chang

Susan S. Witte is associate director, Nabila El-Bassel is director, Louisa Gilbert is codirector, Elwin Wu is associate director and Mingway Chang is statistician, all with the Social Intervention Group, Columbia University School of Social Work, New York.
Couple-based studies offer unique opportunities to examine concordance between partners' reports of behaviorsboth their own and those of their sexual partner-that put them at risk for STDs, including HIV. Extensive research demonstrates that partners' reports of behaviors that they engage in together generally yield fair to good agreement. ${ }^{1-10}$ However, fewer studies have compared partners' reports of risk behaviors that they practice separately (e.g., having concurrent sexual partners) or of STD status. The extent to which individuals' perceptions of their partner's risk behavior or status match their partner's actual risk behavior or status may influence condom use and other protective behaviors, and is indicative of risk for STD transmission. In this study, we examine the agreement of partners' reports of sexual concurrency, history of injection-drug use, recent diagnosis of an STD, HIV status and sex trading (for women only) among 217 heterosexual couples.

\section{BACKGROUND}

Sexual concurrency (i.e., nonmonogamy on the part of one or both members of a couple) is the sexual risk behavior most frequently studied in comparisons of partner reports. Discordant reports of concurrency are especially important because increasing evidence demonstrates that they are associated with the likelihood of STD infection.
Drumright et al., ${ }^{11}$ using a sample of 96 couples recruited from STD and family planning clinics, found that only $26 \%$ of individuals whose partners were nonmonogamous were aware of it; their multivariate analyses demonstrated that STD diagnosis was positively associated both with a partner's nonmonogamy and with an individual's lack of awareness of that behavior. These findings are consistent with those of Boyer et al., ${ }^{12}$ whose study of 2,288 women enrolled in recruit training for the U.S. Marine Corps indicated that women who even had the perception that their partner was nonmonogamous had an increased likelihood of having an STD.

Agreement on reports of sexual concurrency among adult heterosexual couples is fair to good, but men's reports of whether their partner has concurrent partners typically are more accurate than women's reports. ${ }^{5,13}$ For example, Lenoir et al. ${ }^{14}$ found that among 90 adolescent couples who believed that their partner was monogamous, $16 \%$ of female partners and $37 \%$ of male partners had concurrent partners.

Other behaviors examined in concordance studies have included couples' reports of injection-drug use, history of sex work, HIV transmission and other STD transmission. In a sample of 151 heterosexual couples in which the index partner had either a gonococcal or a chlamydial infection, Stoner et al. ${ }^{15}$ found moderate agreement in reports 
of injection-drug use by the partner; agreement was low, however, for reports of the partner's nonmonogamy, history of sex work and history of having visited a sex worker. Ellen et al. ${ }^{16}$ studied 100 couples recruited at public STD clinics and found that more than a third gave discordant reports on sexual concurrency and on ever having injected drugs. Niccolai et al. ${ }^{17}$ found that among 94 couples with one HIV-infected partner, $42 \%$ of men and women who believed that their partner was uninfected were incorrect in that belief.

Some studies have examined individual and relationship characteristics associated with a lack of awareness of risk or discordance of reporting among couples. ${ }^{18,19}$ In a study of 144 couples in whom the husband was entering drug treatment and was sexually active, Fals-Stewart et al. ${ }^{18}$ found that $71 \%$ of wives were not aware that their husband had recently engaged in either unprotected intercourse with another partner or risky needle injection (e.g., using syringes that others had used or that had not been cleaned before use, or using the same cooker, cotton or rinse water that others had used); duration of marriage was positively associated with wives' likelihood of being unaware of their husband's risk behaviors. Riehmann et al. ${ }^{19}$ found few individual and relationship characteristics associated with sexual concurrency among 94 drug or alcohol users and their partners.

These studies have laid important groundwork for the growing literature on concordance in partner reports and its association with risk. However, they were based on relatively small samples, which were recruited predominantly from STD clinics. Research using larger and more diverse samples, and incorporating a wider range of outcome and predictor variables, is needed to more clearly identify individuals or groups whose awareness of their STD risk is relatively low, and to better tailor the content of risk reduction interventions targeting couples.

In this study, we seek to close some of the gaps in the literature on concordance by using a larger sample of couples at high risk of STD transmission, who were recruited from a range of outpatient health care clinics, and examining a wider range of both outcomes and possible predictors in an effort to identify characteristics associated with a lack of awareness of partner risk.

\section{METHODS}

Study data are from a randomized clinical trial testing the efficacy of an intervention designed to reduce sexual risk behaviors among heterosexual couples at risk for STD transmission. ${ }^{20-22}$ The study took place between 1997 and 2002. Female patients attending any of eight outpatient specialty clinics (e.g., prenatal, infectious disease, dental) affiliated with one urban hospital were recruited and screened for participation; eligible women recruited their male partners to participate. A woman was eligible if she was 18-55 years old; had a regular male sexual partner whom she identified as a boyfriend, spouse or lover; was in a long-term relationship with this partner (i.e., had been involved with him for at least the past six months and intended to stay with him for at least another year); reported at least one episode of unprotected vaginal or anal sex with him in the past 30 days; and did not report any life-threatening abuse by him within the past six months. To be eligible, a woman also had to know or suspect that her partner met at least one of the following risk criteria: He had had sex with another partner (male or female) in the past 90 days; he had received a diagnosis of or exhibited symptoms of an STD in the past 90 days; he had injected drugs in the past 90 days; or he was HIVpositive. More detailed descriptions of the study's design, including recruitment and enrollment strategies, are available elsewhere. ${ }^{20,21,23}$

A total of 217 couples were eligible and, after providing informed consent, completed face-to-face baseline interviews. Male staff interviewed the male partner, and female staff interviewed the female partner in a private, separate office. Interviews lasted approximately 90 minutes, and participants were compensated $\$ 30$ for their time. Following completion of the baseline interview, couples were randomized to one of three study conditions. Followup interviews were completed with both the women and the men at three months, and with the women only at 12 months. Data for this article are from the baseline assessments of all 434 participants.

\section{Measures}

-Risk behavior. Participants were asked whether they had had sexual partners other than the partner enrolled in the study in the past 90 days; whether their partner had had other sexual partners during that interval; whether they had ever injected drugs; whether their partner had ever injected drugs; whether they had received an STD diagnosis in the past 90 days; whether their partner had received an STD diagnosis during that period; whether they were HIV-infected; whether their partner was HIV-infected; and whether they had traded sex for money or drugs in the past 90 days (asked of and about women only).24,25

-Demographic characteristics. Information was collected on participants' age, race and ethnicity, marital status, income, education and self-reported HIV status.

-Relationship characteristics. Three measures assessed relationship characteristics. Comfort with sexual issues and one's own sexuality was measured using a 10-item scale (e.g., "How comfortable would you feel talking to [partner] about sex?" and "How comfortable would you feel putting a condom on [partner]?"). ${ }^{26}$ Response options ranged from 1 , denoting "very uncomfortable," to 5, signifying "very comfortable." Thus, total scores ranged from 10 to 50; the higher the score, the greater the sexual comfort. The measure demonstrated good internal reliability (alpha=0.79).

Relationship satisfaction was measured using the sevenitem Relationship Assessment Scale (e.g., "How well does [partner] meet your needs?" and "In general, how satisfied are you with your relationship?"). ${ }^{27,28}$ Responses options 
ranged from 1 to 5 , and total scores ranged from 7 to 35 . The wording of responses varied with the question (e.g., "poorly" to "extremely well" and "unsatisfied" to "extremely satisfied"); in all cases, the higher the score, the greater the relationship satisfaction. This scale, which is highly correlated with the widely used (but much longer) Dyadic Adjustment Scale, ${ }^{29}$ demonstrates good test-retest reliability and consistent measurement properties across samples of couples of diverse ethnicities and ages (alpha=0.82).

Relationship confidence was measured using a single item that asked participants how confident they were that they would remain in the relationship for at least the next 12 months; responses were rated on a five-point scale ( $1=$ not confident, $5=$ very confident). This variable was created as a screening criterion for study eligibility, requiring a response of 4 or 5 . Because it was a single item, measured on an ordinal scale, and because at baseline most individuals responded with a 4 or 5 , we dichotomized it to distinguish participants with more confidence ( 4 or 5 ) from those reporting little or no confidence (1, 2 or 3$)$.

\section{Analysis}

We used frequency distributions to illustrate sample characteristics and t tests to identify differences between males' and females' characteristics. The kappa statistic was used to determine concordance of partners' reports of risk behaviors, controlling for concordance that would be expected because of chance. A kappa value of 0-0.20 indicates poor agreement, 0.21-0.40 fair agreement, 0.41-0.60 moderate agreement, $0.61-0.80$ substantial agreement, and 0.81 or above excellent agreement. ${ }^{30,31}$ However, kappas may be very low when behaviors are reported at a very high or very low frequency by both partners, even if a relatively small proportion of reports are actually inconsistent; ${ }^{32}$ in such instances, the result is an overly conservative estimate of agreement. Therefore, we used percentage agreement (defined as the number of matching responses between partners for a single measure divided by the number of couples) to support interpretation of kappa statistics and to highlight areas of discordance in partner reports.

Multivariate logistic regressions were used to examine the associations between individuals' awareness of STD risk and their demographic and relationship characteristics. Lack of awareness of each risk among participants of each gender was estimated by two models. The first included male participants' characteristics and responses to relationship variables as independent variables; the second included female participants' characteristics and responses to relationship variables as independent variables. We used these two models for two reasons. First, this approach avoids the multicollinearity issue that arises because of the high correlations among male and female characteristic and relationship variables in partnerships when included in a single model. Second, an effective logistic regression model of rare events (i.e., only a few participants are

\begin{tabular}{|c|c|c|}
\hline Characteristic & $\begin{array}{l}\text { Women } \\
(\mathrm{N}=217)\end{array}$ & $\begin{array}{l}\text { Men } \\
(\mathrm{N}=217)\end{array}$ \\
\hline Mean age (range, 18-55 for women, & $36.4(8.2)$ & $38.7(9.6)$ \\
\hline \multicolumn{3}{|l|}{ Race/ethnicity } \\
\hline Black & 54 & 55 \\
\hline Latino & 40 & 38 \\
\hline Other & 6 & 7 \\
\hline \multicolumn{3}{|l|}{ Marital status } \\
\hline Never-married & 60 & 55 \\
\hline Divorced/separated/widowed & 25 & 31 \\
\hline Married & 15 & 14 \\
\hline \multicolumn{3}{|l|}{ Income* } \\
\hline$<\$ 5,000$ & 68 & 50 \\
\hline$\$ 5,000-9,999$ & 19 & 23 \\
\hline$\$ 10,000-19,999$ & 9 & 16 \\
\hline$\geq \$ 20,000$ & 4 & 11 \\
\hline \multicolumn{3}{|l|}{ Education } \\
\hline$<$ high school & 66 & 65 \\
\hline High school & 16 & 16 \\
\hline$>$ high school & 18 & 19 \\
\hline \multicolumn{3}{|l|}{ HIV status } \\
\hline Negative & 70 & 68 \\
\hline Positive & 22 & 20 \\
\hline Unknown & 8 & 12 \\
\hline \multicolumn{3}{|l|}{ Relationship confidence* } \\
\hline Not confident & 7 & 11 \\
\hline Confident & 93 & 89 \\
\hline Mean sexual comfort (range, 10-50)* & $41.1(8.7)$ & $44.7(5.4)$ \\
\hline $\begin{array}{l}\text { Mean relationship satisfaction } \\
(\text { range, } 7-35)^{*}\end{array}$ & $27.9(5.2)$ & $29.1(4.3)$ \\
\hline
\end{tabular}

${ }^{*} \mathrm{p} \leq$.01. Notes: Unless otherwise noted, data are percentages. Differences between genders were assessed in t tests. Figures in parentheses are standard deviations. Men's reports of income, relationship and sexual comfort were based on 216 responses.

unaware of the risks) cannot properly converge when too many predictors are included (and, in fact, did not do so when we ran a single model). Furthermore, to compare coefficients across the male and female models for each risk, the seemingly unrelated estimation module in Stata 10 was applied after logistic regressions. It estimated the joint variance and covariance matrix of the sandwich, or robust, type to perform comparisons across two models that can test whether males' and females' characteristics have similar associations with lack of awareness.

\section{RESULTS}

\section{Demographic Characteristics}

Male and female members of the sample were generally similar in their demographic characteristics (Table 1), although on average, women were slightly younger than men (36.4 vs. 38.7 years). Most were black or Latino, had never been married, had less than a high school education and were HIV-negative; two-thirds of women and half of men were of low socioeconomic status (i.e., reported an income less than $\$ 5,000$ annually). Nine in 10 participants 
TABLE 2. Percentage distribution of participants, by agreement between their reports and their partner's reports of their partner's risk behavior, according to gender

\begin{tabular}{|c|c|c|}
\hline Behavior & Female & Male \\
\hline $\begin{array}{l}\text { Partner has been nonmonogamous } \\
\text { in the past } 90 \text { days }\end{array}$ & $(\mathrm{N}=129)$ & $(\mathrm{N}=176$ \\
\hline Both say yes & 12.4 & 6.3 \\
\hline Both say no & 59.7 & 74.4 \\
\hline Says yes, partner says no & 24.8 & 5.1 \\
\hline Says no, partner says yes & 3.1 & 14.2 \\
\hline Kappa & 0.32 & 0.29 \\
\hline Partner ever injected drugs & $(\mathrm{N}=210)$ & $(\mathrm{N}=213$ \\
\hline Both say yes & 20.5 & 17.8 \\
\hline Both say no & 61.9 & 68.1 \\
\hline Says yes, partner says no & 7.1 & 2.3 \\
\hline Says no, partner says yes & 10.5 & 11.7 \\
\hline Kappa & 0.58 & 0.63 \\
\hline $\begin{array}{l}\text { Partner received an STD diagnosis } \\
\text { in the past } 90 \text { days }\end{array}$ & $(\mathrm{N}=215)$ & $(\mathrm{N}=215$ \\
\hline Both say yes & 0.5 & 0.5 \\
\hline Both say no & 88.8 & 86.5 \\
\hline Says yes, partner says no & 0.9 & 1.4 \\
\hline Says no, partner says yes & 9.8 & 11.6 \\
\hline Kappa & 0.06 & 0.04 \\
\hline Partner's HIV status & $(\mathrm{N}=179)$ & $(\mathrm{N}=188$ \\
\hline Perceives positive, partner says positive & 20.1 & 20.2 \\
\hline Perceives negative, partner says negative & 74.9 & 75.0 \\
\hline Perceives positive, partner says negative & 2.8 & 1.1 \\
\hline Perceives negative, partner says positive & 2.2 & 3.7 \\
\hline Kappa & 0.86 & 0.86 \\
\hline Partner traded sex in the past 90 days & & $(\mathrm{N}=171)$ \\
\hline Both say yes & na & 1.2 \\
\hline Both say no & na & 93.0 \\
\hline Says yes, partner says no & na & 1.2 \\
\hline Says no, partner says yes & na & 4.7 \\
\hline Kappa & na & 0.26 \\
\hline
\end{tabular}

were confident that they would stay in their current relationship at least through the next year. Men reported a slightly higher average level of sexual comfort than women (44.7 vs. 41.1 ), as well as slightly greater relationship satisfaction (29.1 vs. 27.9).

\section{Concordance of Actual and Perceived Risk}

Three percent of women and $14 \%$ of men were unaware that their partner had been nonmonogamous in the past 90 days (Table 2). Eleven percent of women and 12\% of men were unaware that their partner had a history of injection-drug use; $10 \%$ and $12 \%$, respectively, were unaware that their partner had had an STD diagnosed within the past 90 days, and 2\% and 4\% were unaware that their partner was HIV-positive. Five percent of men were unaware that their female partner had traded sex for money or drugs in the past 90 days. Kappa values were highest for awareness of partners' HIV status (0.9 for both women and men) and history of injection-drug use (0.6 for both), suggesting moderate to excellent agreement. Agreement was fair for awareness of partners' nonmonogamy ( 0.3 for both women and men); it was poor for awareness of partners' STD diagnosis in the prior 90 days ( 0.1 and 0.04 for women and men, respectively), probably because large proportions of men and women reported agreement on this issue.

\section{Predictors of Lack of Awareness of Partner Risk}

-Women. The older women were, the more likely they were to be unaware of their male partner's injection-drug use history (odds ratio, 1.1-Table 3). Women who identified their ethnicity as other than black or Latina were more likely to be unaware of their male partner's injectiondrug use history than were blacks (15.8). The odds that women were unaware of their partner's ever having used injection drugs also increased with both partners' relationship satisfaction (1.2 for each).

Women's likelihood of being unaware of their partner's recent STD diagnosis increased with age (odds ratio, 1.1) and was higher among women with Latino partners than among those whose partners were black (3.7). It also was positively associated with men's reporting that they were married (4.4), although it was not related to women's reports of their marital status. Women who were confident that they would remain in their relationship were less likely than others to be unaware that their partner had recently received an STD diagnosis (0.1).

-Men. Men's odds of being unaware that their female partner had a history of injection-drug use increased with her age (odds ratio, 1.1).

Men's own age was directly, and positively, associated with their likelihood of being unaware that their female partner was HIV-positive (odds ratio, 1.1); the odds of this outcome also were elevated if the partner was formerly married, as opposed to never-married (8.2). The odds that men were unaware of their partner's HIV infection were reduced if the partner had less than a high school education (0.1) or was confident in the relationship (0.1). None of the comparisons of coefficients across models were significant at the 5\% level; thus, men's and women's characteristics had similar associations with lack of awareness.

\section{DISCUSSION}

Findings from this study confirm those of earlier, similar studies: In general, concordance on risk behaviors between partners is good. ${ }^{1-11,13-19,33}$ However, also consistent with prior studies, our results highlight that some women and men are unaware of partners' risk behaviors and STD status, and may therefore develop a false sense that they are protected from infection. ${ }^{5,11,13-19,33}$ In this study, agreement of perceived and actual risk was high in reports of HIV status and awareness of injection-drug use history. Agreement was low for awareness of sexual concurrency.

The finding of low agreement and underestimates for partners' nonmonogamy is consistent with findings from other studies..$^{511-14}$ This is an important finding because misperception of this risk behavior, whether overestimation or underestimation, may be associated with an elevated likelihood of STD transmission. ${ }^{11,12}$ It is noteworthy that our findings were not consistent with those of other studies ${ }^{5,13,15,16,18,19}$ with respect to gender. For example, we 
found that 3\% of women and 14\% of men underestimated their partner's nonmonogamy. In studies using samples that were not restricted by gender, Stoner et al. ${ }^{15}$ and Riehman et al. ${ }^{19}$ found that $35-38 \%$ of participants underestimated their heterosexual partner's recent concurrency. In studies with gender-specific samples, Ellen et al., ${ }^{16}$ Fals-Stewart et al., ${ }^{18}$ Seal $^{5}$ and Harvey et al. ${ }^{13}$ all found that women were less aware than men that their partner had had a concurrent partner. One potential explanation for the disparate findings is that our sample may have been subject to self-selection bias: We recruited women who were in relationships marked by risky (or suspected risky) behaviors and had them recruit their male partners; perhaps women who enrolled in the study were more interested than others in either disclosing their own risky behaviors or discovering their partners'. Alternatively, because awareness of male partners' concurrency was one of several risk-related eligibility criteria for our study, women in this sample may have been particularly aware of their partner's concurrency. Finally, the women in the sample may simply have adhered to a commonly held sexual double standard and assumed that their partner had other partners, indicating an issue of reporting bias.

In contrast to the literature reporting that men more often than women underestimate their partner's history of injection-drug use, ${ }^{15,16}$ we found no difference. In our sample, $11 \%$ of women and $12 \%$ of men were unaware that their partner had ever injected drugs. In a study by Ellen et al., ${ }^{16}$ the proportions were $25 \%$ and $45 \%$, respectively; Stoner et al. ${ }^{15}$ found that $4 \%$ of couples were unaware that their partners had used injection drugs.

A much lower proportion of men in our study than in the study by Stoner et al. ${ }^{15}$ underestimated their female partner's involvement in sex work-5\% vs. 15\%. This finding may be due to self-selection bias. Sex work is highly stigmatized. Perhaps women who enrolled in the study had disclosed their sex work to their partners or were aware that their partners knew of their engagement in sex work. Alternatively, we may have enrolled a sample of women who were less likely to be engaged in sex work than were those in Stoner's study. Yet another interpretation could be that male partners in this sample were already aware of their partner's sex work, as drugs are often traded instead of money in this poor neighborhood, and drugusing males frequently know of and support their female partner's engaging in sex work for drugs.

Our finding that $10 \%$ of females and $12 \%$ of males were unaware of their partner's recent diagnosis of an STD is novel. This finding has important implications for understanding risk, because having an STD is a cofactor for transmission of HIV and other STDs.

Our multivariate findings are difficult to interpret. Risk behaviors are not equal in terms of the potential risk they pose to an unprotected partner. For example, a newly diagnosed STD indicates that recent partners have been exposed to the risk of infection, whereas past injectiondrug use may or may not indicate potential risk.

\begin{tabular}{|c|c|c|c|c|}
\hline \multirow[t]{2}{*}{ Characteristic } & \multicolumn{2}{|c|}{ Women's unawareness } & \multicolumn{2}{|c|}{ Men's unawareness } \\
\hline & $\begin{array}{l}\text { Partner's past } \\
\text { drug use }\end{array}$ & $\begin{array}{l}\text { Partner's } \\
\text { STD status }\end{array}$ & $\begin{array}{l}\text { Partner's past } \\
\text { drug use }\end{array}$ & $\begin{array}{l}\text { Partner's } \\
\text { HIV status }\end{array}$ \\
\hline \multicolumn{5}{|l|}{ Women } \\
\hline \multicolumn{5}{|l|}{ Race/ethnicity } \\
\hline Black (ref) & 1.00 & 1.00 & 1.00 & 1.00 \\
\hline Latino & $0.95(0.32-2.85)$ & $2.15(0.64-7.20)$ & $2.40(0.95-6.11)$ & $1.76(0.37-8.32)$ \\
\hline Other & $15.82^{* *}(3.82-65.47)$ & $3.96(0.63-24.90)$ & $4.11(0.65-25.95)$ & na \\
\hline \multicolumn{5}{|l|}{ Marital status } \\
\hline $\begin{array}{l}\text { Never-married } \\
\text { (ref) }\end{array}$ & 1.00 & 1.00 & 1.00 & 1.00 \\
\hline $\begin{array}{l}\text { Divorced/sepa- } \\
\text { rated/widowed }\end{array}$ & $0.95(0.26-3.41)$ & $0.54(0.12-2.38)$ & $0.49(0.12-2.07)$ & $8.23 *(1.01-67.08)$ \\
\hline Married & $0.94(0.21-4.19)$ & $2.82(0.80-9.91)$ & $1.51(0.45-5.13)$ & $6.63(0.34-128.96)$ \\
\hline \multicolumn{5}{|l|}{ Education } \\
\hline$<$ high school (ref) & 1.00 & 1.00 & 1.00 & 1.00 \\
\hline zhigh school & $0.85(0.29-2.48)$ & $0.88(0.27-2.88)$ & $0.30(0.08-1.12)$ & $0.07^{*}(0.01-0.58)$ \\
\hline Sexual comfort & $0.98(0.92-1.04)$ & $1.04(0.98-1.11)$ & $1.01(0.96-1.07)$ & $1.09(0.95-1.25)$ \\
\hline \multicolumn{4}{|l|}{ Relationship } & $0.87(0.74-1.02)$ \\
\hline \multicolumn{4}{|l|}{ Confident in } & $0.05^{* *}(0.01-0.39)$ \\
\hline \multicolumn{5}{|l|}{ Men } \\
\hline Age & $1.01(0.97-1.06)$ & $1.03(0.98-1.08)$ & $1.03(0.98-1.08)$ & $1.07^{*}(1.01-1.14)$ \\
\hline \multicolumn{5}{|l|}{ Race/ethnicity } \\
\hline Black (ref) & 1.00 & 1.00 & 1.00 & 1.00 \\
\hline Latino & $0.86(0.32-2.33)$ & $3.72^{*}(1.31-10.58)$ & $2.14(0.83-5.49)$ & $0.69(0.13-3.74)$ \\
\hline Other & $1.15(0.19-7.04)$ & na & $1.24(0.22-6.90)$ & $1.47(0.12-18.80)$ \\
\hline \multicolumn{5}{|l|}{ Marital status } \\
\hline $\begin{array}{l}\text { Never-married } \\
\text { (ref) } \\
\text { Divorced/sepa- }\end{array}$ & 1.00 & 1.00 & 1.00 & 1.00 \\
\hline $\begin{array}{l}\text { Divorced/sepa- } \\
\text { rated/widowed }\end{array}$ & $0.87(0.29-2.59)$ & $0.53(0.10-2.67)$ & $1.51(0.48-4.68)$ & $0.82(0.08-7.97)$ \\
\hline Married & $1.03(0.25-4.24)$ & $4.42 *(1.32-14.77)$ & $0.54(0.10-2.79)$ & $2.92(0.38-22.54)$ \\
\hline \multicolumn{5}{|l|}{ Education } \\
\hline$<$ high school (ref) & 1.00 & 1.00 & 1.00 & 1.00 \\
\hline 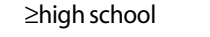 & $0.78(0.27-2.26)$ & $0.51(0.14-1.93)$ & $0.85(0.34-2.12)$ & $0.22(0.02-2.08)$ \\
\hline Sexual comfort & $0.92(0.85-1.01)$ & $1.02(0.95-1.11)$ & $0.99(0.93-1.06)$ & $0.98(0.87-1.10)$ \\
\hline $\begin{array}{l}\text { Relationship } \\
\text { satisfaction }\end{array}$ & $1.19^{* *}(1.06-1.34)$ & $1.02(0.91-1.15)$ & $1.00(0.89-1.12)$ & $0.99(0.84-1.17)$ \\
\hline $\begin{array}{l}\text { Confident in } \\
\text { relationship }\end{array}$ & $0.50(0.08-2.99)$ & $0.54(0.12-2.40)$ & $4.09(0.72-23.16)$ & $0.55(0.04-7.44)$ \\
\hline
\end{tabular}

${ }^{*} \mathrm{p}<.05 .{ }^{* *} \mathrm{p}<.01$. Notes: ref=reference group. na=not applicable, because variable was omitted from the model. Relationship confidence was a dichotomous measure; all other characteristics for which no reference group is shown were continuous.

Among women, we found predictors for lack of awareness of partners' injection-drug use and partners' recent STD diagnosis; among men, predictors for partners' injection-drug use and partners' HIV status. Predictors differed for men and women, with two exceptions. First, a female partner's confidence that she would remain in the relationship was protective for both men and women. Although confidence is a difficult variable to operationalize, it suggests commitment to the relationship, to the future of the 
relationship and to anticipated shared experience and events. We cannot determine the direction of this association, but enhanced relationship confidence among couples may be related either to higher levels of communication and disclosure, or to lower levels of risk-taking outside the relationship. Our finding of a positive association between men's relationship satisfaction and women's unawareness of their partner's injection-drug use history runs contrary to the above interpretation, however; it suggests that some men do not disclose some risky behaviors to their partner even when that behavior is in the past. Second, the older women are, the greater is not only their risk of not knowing about a partner's injection-drug use history or STD status, but their partner's risk of not knowing that they have used injection drugs. The implication is that interventions should encourage disclosure of these risk factors between partners of all ages, facilitated by individuals who are trained in STD prevention and can help to ensure the safety of both the partners and their relationship.

Women's lack of awareness of their partner's risky behaviors also was positively associated with being neither black nor Latina, relationship satisfaction, having a Latino partner and being married. Marriage and satisfaction with one's relationships may lead to confidence in the quality of intimacy and trust in a relationship, and may lead partners to believe that they know about each other's recent and long-term history of STD risk behaviors. Findings based on race and ethnicity are difficult

and follow-up. to interpret, as all findings are, in the absence of more context; they may be related to cultural differences in communication and disclosure, suggesting a need for greater understanding of how to reduce barriers to, and encourage, safe communication and risk disclosure in relationships.

Among men, lack of awareness was also associated with having a partner who was divorced, separated or widowed, and with the female partner's level of education. Perhaps more highly educated women and women who have been in a committed relationship before have more experience than others with disclosing risky behaviors to a partner and facing negative consequences of disclosing -including the ending of a relationship_-and therefore tend not to tell partners about such behaviors.

Literature on disclosure of HIV status provides some evidence in support of our findings. While an infected individual is more likely to disclose to his or her partner than to any other significant individual, ${ }^{34}$ women are less likely than men to disclose their HIV status to their partner. ${ }^{35}$ This may explain the number of predictors of men's unawareness of their female partner's HIV-positive status. Women often avoid HIV disclosure out of fear of rejection, abandonment or violence at the hands of their intimate partner. ${ }^{36}$ Among individuals in casual relationships, disclosure of HIV status is somewhat inhibited, ${ }^{37}$ which may explain why men whose female partner was confident in the relationship were more likely than others to be aware of their partner's HIV status.

\section{Study Limitations}

Findings from this study must be considered in light of several limitations. First, all data were self-reported, and we therefore had no confirmation of actual STD status. Thus, our results can suggest the potential for risk, but cannot confirm that perceptions actually lead to risk. Second, some of our assessment questions were based on 90-day reports of behaviors, for which recall may be challenging. Third, interviews were conducted face-to-face, which may have contributed to reporting bias toward "socially acceptable" behaviors. Fourth, all women who were recruited into this study had to either know or believe that their partner was putting them at risk; therefore, findings are limited in their generalizability to urban couples at high risk of STD transmission, as defined by our eligibility criteria. Additionally, this selection criterion may explain why we found more men than women underestimating partner nonmonogamy: Women may have been eligible for and enrolled in the study because they were aware that their partner had had concurrent partners. Finally, in the absence of information to the contrary, individuals may be inclined to believe in the best possible situation-e.g., that partners are monogamous, do not have HIV or any other STD, and have never injected drugs.

\section{Implications}

The findings of this study should cause some satisfaction, but also some concern. Concordance in couples' reporting of risk may be a sign of disclosure and communication within relationships, and of fairly accurate risk assessment among couples. But how do we effectively reduce risk when one partner is receiving false or no information about the other's risk behaviors, and therefore may not be taking necessary precautions to reduce risk? A decade since the first study comparing actual and perceived reports found underestimates of partner risk among heterosexual couples,${ }^{16}$ we find that little has changed.

Discrepancy in partner reports presents challenges to data analysis plans, but can also provide important information for assessing actual risk and, therefore, developing more effective prevention interventions for couples to prevent new STD transmissions.

Couple data should be collected, where and when feasible, to facilitate accurate assessments of risk and behavior change. Couple-based assessments should further explore these issues of real and perceived risk behaviors among couples to better target HIV prevention efforts and to reduce the occurrence of misperceptions and a false sense of security regarding the need for protective behaviors.

Measuring discordance in risk behaviors that couples engage in separately, as well as perceptions of STD status, may enable prevention specialists to better target couples for intervention. Individuals are often afraid to disclose risk behaviors to partners for fear of stigmatization and rejection. Couple-oriented intervention strategies are needed that will allay these fears and concerns, and provide a safe space for disclosure and follow-up. Interventions at 
the couple level may allow for enhanced communication and disclosure, emphasizing the value of the relationship to both partners, which in turn may strengthen commitments to the health of the partnership.

\section{REFERENCES}

1. Padian NS, Sexual histories of heterosexual couples with one HIV-infected partner, American Journal of Public Health, 1990, 80(8):990-991.

2. de Boer MA et al., Reliability of self-reported sexual behavior in human immunodeficiency virus (HIV) concordant and discordant heterosexual couples in northern Thailand, American Journal of Epidemiology, 1998, 147(12):1153-1161.

3. Upchurch DM et al., Interpartner reliability of reporting of recent sexual behaviors, American Journal of Epidemiology, 1991, 134(10):1159-1166.

4. Ellish NJ et al., Reliability of partner reports of sexual history in a heterosexual population at a sexually transmitted disease clinic, Sexually Transmitted Diseases, 1996, 23(6):445-452.

5. Seal DW, Interpartner concordance of self-reported sexual behavior among college dating couples, Journal of Sex Research, 1997, 34(1):39-55

6. Ochs EP and Binik YM, The use of couple data to determine the reliability of self-reported sexual behavior, Journal of Sex Research, 1999, 36(4):374-384

7. Van Duynhoven Y, Nagelkerke N and Van De Laar M, Reliability of self-reported sexual histories: test-retest and interpartner comparison in a sexually transmitted diseases clinic, Sexually Transmitted Diseases, 1999, 26(1):33-42.

8. Padian $\mathrm{N}$ et al., Reliability of sexual histories in heterosexual couples, Sexually Transmitted Diseases, 1995, 22(3):169-172.

9. Sison JD, Gillespie B and Foxman B, Consistency of self-reported sexual behavior and condom use among current sex partners, Sexually Transmitted Diseases, 2004, 31(5):278-282.

10. Witte SS et al., Predictors of discordant reports of sexual and HIV/ STI risk behaviors among heterosexual couples, Sexually Transmitted Diseases, 2007, 34(5):302-308.

11. Drumright LN, Gorbach PM and Holmes KK, Do people really know their sex partners: concurrency, knowledge of partner behavior and sexually transmitted infections within partnerships, Sexually Transmitted Diseases, 2004, 31(7):437-442.

12. Boyer $\mathrm{CB}$ et al., Sociodemographic markers and behavioral correlates of sexually transmitted infections in a nonclinical sample of adolescent and young adult women, Journal of Infectious Diseases, 2006, 194(1):307-315.

13. Harvey SM et al., He said, she said: concordance between sexual partners, Sexually Transmitted Diseases, 2004, 31(3):185-191.

14. Lenoir $\mathrm{CD}$ et al., What you don't know can hurt you: perceptions of sex-partner concurrency and partner-reported behavior, Journal of Adolescent Health, 2006, 38(3):179-185.

15. Stoner BP et al., Avoiding risky sex partners: perception of partners' risks versus partners' self reported risks, Sexually Transmitted Infections, 2003, 79(3):197-201.

16. Ellen JM et al., Individuals' perceptions about their sex partners' risk behaviors, Journal of Sex Research, 1998, 35(4):328-332.

17. Niccolai LM et al., HIV-infected persons' knowledge of their sexual partners' HIV status, AIDS Education and Prevention, 2002, 14(3):183-189

18. Fals-Stewart $\mathrm{W}$ et al., An examination of indirect risk of exposure to HIV among wives of substance-abusing men, Drug and Alcohol Dependence, 2003, 70(1):65-76.
19. Riehman KS et al., Discordance in monogamy beliefs, sexual concurrence, and condom use among young adult substance-involved couples: implications for risk of sexually transmitted infections, Sexually Transmitted Diseases, 2006, 33(11):677-682.

20. El-Bassel $\mathrm{N}$ et al., HIV prevention for intimate couples: a relationship-based model, Families, Systems, and Health, 2001, 19(4):379-395.

21. El-Bassel $\mathrm{N}$ et al., The efficacy of a relationship-based HIV/STD prevention program for heterosexual couples, American Journal of Public Health, 2003, 93(6):963-969.

22. El-Bassel $\mathrm{N}$ et al., Long term effects of an HIV/STI sexual risk reduction intervention for heterosexual couples, AIDS and Behavior, 2005, 9(1):1-13.

23. Witte $S$ et al., Recruitment of minority women and their main, male sexual partners in an HIV/STI prevention trial, Journal of Women's Health, 2004, 13(10):1137-1147.

24. El-Bassel $\mathrm{N}$ et al., Correlates of crack abuse among incarcerated women: psychological trauma, social support and coping behavior, American Journal of Drug and Alcohol Abuse, 1996, 22(1):41-56.

25. El-Bassel $\mathrm{N}$ et al., Preventing HIV/AIDS in drug-abusing incarcerated women through skills-building and social support enhancement: preliminary outcomes, Social Work Research, 1995, 19(3):131-141.

26. Marín BV et al., Condom use in unmarried Latino men: a test of cultural constructs, Health Psychology, 1997, 16(5):458-467.

27. Hendrick SS, A generic measure of relationship satisfaction, Journal of Marriage and the Family, 1988, 50(1):93-98.

28. Hendrick SS, Dicke A and Hendrick C, The Relationship Assessment Scale, Journal of Social \& Personal Relationships, 1998, 15(1):137-142.

29. Spanier GB, Measuring dyadic adjustment: new scales for assessing the quality of marriage and similar dyads, Journal of Marriage and the Family, 1976, 38(1):15-28.

30. Fleiss JL, Statistical Methods for Rates and Proportions, second ed., New York: Wiley, 1981.

31. Landis JR and Koch GG, The measurement of observer agreement for categorical data, Biometrics, 1977, 33(1):159-174.

32. Cichetti DV and Feinstein AR, High agreement but low kappa. II: resolving the paradoxes, Journal of Clinical Epidemiology, 1990, 43(6):551-558.

33. Brewer DD et al., Agreement in reported sexual partnership dates and implications for measuring sexual concurrency, Sexually Transmitted Diseases, 2006, 33(5):277-283.

34. Simoni JM et al., Women's self-disclosure of HIV infection: rates, reasons and reactions, Journal of Consulting and Clinical Psychology, 1995, 63(1):474-478.

35. Kalichman SC and Nachimson D, Self-efficacy and disclosure of HIV-positive serostatus to sex partners, Health Psychology, 1999, 18(1):281-285.

36. Gielen AC et al., Women living with HIV: disclosure, violence and social support, Journal of Urban Health, 2000, 77(3):480-491.

37. Serovich JM and Mosack KE, Reasons for HIV disclosure or nondisclosure to casual sexual partners, AIDS Education and Prevention, 2003, 15(1):70-80

\section{Acknowledgment}

This study was supported by National Institute of Mental Health grant MH57145.

Author contact: ssw12@columbia.edu 